Ополев Павел Валерьевич - кандидат философских наук, доцент, доцент кафедры философии Сибирского государственного автомобильно-дорожного университета. Адрес: 644080, Россия, г. Омск, пр. Мира, А. 5. Тел.: +7 (3812) 65-33-54. Эл. адрес: pvo-sinergetica@rambler.ru

Opolev Pavel Valeryevich, Candidate of Philosophy, Associate Professor, Associate Professor, Department of Philosophy, Siberian State Automobile and Highway University. Postal address: 5, Mira Ave., Omsk, Russian Federation, 644080. Tel: +7 (3812) 65-33-54. E-mail: pvo-sinergetica@rambler.ru

DOI: $10.17805 /$ zpu.2019.4.13

\title{
Развитие взглядов на феномен «чужого» в истории культуры
}

\author{
М. А. ПОЛЕТАЕВА \\ МОСКОВСКИЙ ГОСУДАРСТВЕННЫЙ ЛИНГВИСТИЧЕСКИЙ УНИВЕРСИТЕТ
}

В статье дается обзор эволюции представлений о своем и чужом человеке в истории человечества. Это первая попытка комплексной научной систематизации типовых взглядов общества на эту проблему в истории, игравших значимую роль в становлении национальной идентичности людей.

В первую очередь рассматриваются различные варианты членения истории на периоды и обосновывается значимость ее членения на технологические эпохи: доиндустриальную, индустриальную и постиндустриальную. Развертываются нужные для данного исследования характеристики каждой эпохи и показывается, почему в каждую эпоху различалось отношение к дихотомии свой/чужой.

Для доиндустриальной эпохи было свойственно восприятие чужого как существа вредного, с которым следует иметь дело как можно меньше и реже контактировать. Чужой - это враг, порождение дьявола, и с ним всегда нужно быть настороже.

В индустриальную эпоху чужой воспринимался как человек, отличающийся от местного, но не опасный. Взаимодействовать с ним можно, особенно при его достаточной ассимиляции в местной среде.

В постиндустриальную эпоху чужой воспринимается уже лишь как культурно другой, но тем и интересный человек. Взаимодействие с ним возможно, так же как и со своим.

Таким образом, в истории имела место определенная эволюция отношения общества к чужому от его максимального отторжения к его преимущественному приятию.

Ключевые слова: свой; чужой; доиндустриальная эпоха; индустриальная эпоха; постиндустриальная эпоха; история культуры

\section{ВВЕАЕНИЕ}

$\Pi$ редставления о чужом были разными в разные эпохи. Особенности этих представлений в существенной мере определялись мировоззренческими характеристиками этих эпох, параметрами картин мира людей, живших в разное время. Поэтому, прежде чем приступать к рассмотрению особенностей такого отношения к чужим, нужно определиться с принципами членения истории на эпохи.

В мировой науке существует множество вариантов членения истории на различные периоды, созданные на протяжении многих веков и опирающиеся на разные основания. Это и социально-экономические формации, и культурно-цивилизационные эпохи, и религиозные эры, и т. п. Из этого множества вариантов мы выбираем сравни- 
тельно новую концепцию членения истории на технологические периоды, т. е. эпохи, основанные на господстве разных типов технологий, - доиндустриальную, индустриальную и постиндустриальную (Белл, 1999; Фукуяма, 2004 и др.). При этом под «индустриальностью» понимается машинное производство каких-либо материальных предметов или фрагментов сооружений. Соответственно, доиндустриальная эпоха - это время до появления производящих машин (время ручного инструментария), а постиндустриальная эпоха - это время, когда машины перестали играть самодовлеющую роль, а стали чисто техническими элементами производства, главным же стало автоматизированное управление машинами и производство нового знания.

Выбор именно этого варианта членения истории для данного исследования обусловлен тем, что развитие типов технологий материального производства, а с ними и типов социального устроения общества в конечном счете очень влияло на становление и укрепление той или иной типологии общественного сознания и его базовых характеристик (Костина, Флиер, 2009; Флиер, 2012), а также на параметры идентичности людей и разделения социального мира на своих и чужих (Шапинская, 2011). Поскольку именно этот параметр общественного сознания является основным объектом нашего исследования, то выбор концепции понимания истории, наиболее способствующей такому анализу, представляется оптимальным.

\section{ХАРАКТЕРИСТИКИ ЭПОХ}

Аоиндустриальная эпоха, в которую принято включать этапы первобытный, рабовладельческий и феодальный, характеризовалась преобладанием ручного труда (как индивидуального, так и коллективного), доминированием мифологических и религиозных верований в общественном сознании и представлениях о социальном мироустройстве, а также исключительно непосредственной межличностной коммуникацией (устной и письменной) между индивидами.

Эту эпоху определяют временным отрезком от возникновения человечества (примерно 40 тыс. лет назад) до рубежа XV-XVI вв. - времени Великих географических открытий, изобретения печатного станка, начала итальянского Возрождения в искусстве и общественной мысли и т. п., а главное - до начала использования первых машинных устройств в некоторых видах ремесла (например, ткачестве).

Аоминирующее религиозное сознание людей того времени заставляло их видеть все сущее преимущественно в ракурсе религиозной значимости объектов бытия и даже социальную справедливость определять по ее мистической богоугодности. Общая направленность сознания общества доиндустриальной эпохи была связана с сакрализацией своего прошлого, поклонением «великим предкам», легендарным героям и религиозным подвижникам минувших веков как важнейшим эталонным образцам правильного социального поведения, подражание которым является единственно верным жизненным путем.

Индустриальная эпоха характеризовалась машинным производством с ручным управлением (станки, непосредственно управлявшиеся рабочими), преобладающим рациональным массовым сознанием общества и стремлением к переустройству мира на основаниях большей социальной справедливости (демократии), а также обезличенной коммуникацией в виде массово тиражируемых книг и газет, а позднее радио и телевидения. В целом культуру индустриального общества принято называть «книжной» по особой роли книги в систематизации представлений людей о бытии. Индустриальная эпоха занимает временной отрезок от рубежа XV-XVI вв. до 60-х гг. XX в. 
Это привычные для нас капитализм и социализм, которые при всем своем политикоидеологическом различии основывались на едином типе технологий материального производства.

Увлечение идеями социального равноправия тем не менее с трудом уживалось с концепцией равноправия национально-культурного, чем было порождено множество политических коллизий, и в первую очередь колониализм - завоевание и әксплуатация слаборазвитых народов Азии, Африки, Аатинской Америки. При әтом общая направленность общественного сознания была связана не столько с сакрализацией прошлого, сколько с романтизацией будущего, с мечтами о построении прекрасного справедливого общества (в той или иной форме), безостановочном научно-техническом прогрессе, освоении Космоса и т. п., ради чего нужно перетерпеть плохое настоящее.

Постиндустриальная эпоха, начало которой обычно отсчитывается от 60-х гг. ХХ в., в частности от «студенческого бунта» 1968 г. в Европе, движения хиппи в США, но главное - изобретения компьютера, буквально «перевернувшего мир» внедрением информационных технологий. Эпоха постиндустриализма характеризуется машинным производством с электронным автоматизированным управлением, господством критического массового сознания (подвергающего сомнению все концепции объяснения наблюдаемого мира), а также гиперкоммуникацией с помощью компьютеров, мобильных телефонов и іPhon, практически не имеющих границ по охвату мира и создающих глобальное информационное поле всего человечества. Это формирующийся сейчас посткапитализм с его глобализацией, тотальной информатизацией и пр. Сразу же объяснимся, что под посткпитализмом мы понимаем капиталистическое производство, основанное на частной инициативе, сочетаемое с социалистическими стандартами в вопросах обеспечения прав и нужд населения (Mason, 2015).

Массовое сознание постиндустриального мира ориентировано прежде всего на проблемы социальной свободы и равноправия людей, включающие и равноправие национально-культурное. Постиндустриальное общественное сознание уже не сакрализует прошлое и не романтизирует будущее, а сосредоточено на настоящем и его проблемах, современное решение которых мало удовлетворяет общество.

Но нужно помнить и о том, что если первобытными когда-то были все ныне существующие и когда-либо существовавшие народы, то лишь сравнительно небольшая их часть достигла аграрной стадии развития, малая часть последних перешла на индустриальную стадию и лишь чуть более десятка народов (пока) доросло до постиндустриальной стадии развития. Бо́льшая часть народов Земли остановилась в своей социальной эволюции на том или ином этапе, не найдя ресурсов для дальнейшего развития; и лишь несколько народов (полтора-два десятка) развились до постиндустриальной стадии. Так что на Земле сейчас представлены практически все исторические эпохи в лице разных народов. Сегодня большая часть человечества живет при первобытном строе и аграрном феодализме (в доиндустриальную эпоху), меньшая часть при капитализме и социализме (в индустриальную эпоху) и лишь несколько стран при посткапитализме (в постиндустриальную эпоху). К тому же во многих странах наблюдается ситуация, когда крупные города живут в постиндустриальных условиях, а глубокая провинция - еще при феодализме. Таков современный мир.

\section{ПРЕАСТАВАЕНИЯ О СВОЕМ И ЧУЖОМ В АОИНАУСТРИААЬНУЮ ЭПОХУ}

В разные эпохи и при разных типах доминирующего массового сознания были актуальны и разные представления о своих и чужих людях. В истории человечества сло- 
жились три типа отношения к чужому: сначала в доиндустриальную эпоху чужой воспринимался плохим, и иметь с ним дело считалось опасным (Флиер, 2006; Флиер, 2019); затем в индустриальную эпоху чужой определялся как «другой», и иметь с ним дело считалось возможным, но сложным; и наконец, сейчас, в постиндустриальную эпоху, чужой воспринимается как хороший, и иметь с ним дело считается не более опасным, чем со своим.

В доиндустриальную эпоху, в трех ее последовательных периодах - родовом, племенном, аграрном этно-государственном, - в общественном сознании преобладали разные способы определения чужого.

В родовой первобытной общине дихотомия свой/чужой основывалась преимущественно на оппозиции сородич/инородец. Инородец не просто разговаривал на ином языке и придерживался иных обычаев, но - главное - он считал свое происхождение от иного «великого предка», иного тотема. В родовой общине статус кровного родственника являлся наиболее значимым. Позднее это все вылилось в институт многочисленной родни, которая в европейской культурной традиции обычно составляет до двух десятков человек, а у некоторых народов Востока насчитывает иногда более сотни людей. И всех их человек обязан помнить и знать обязанности каждого родственника по отношению к себе и свои обязанности по отношению к каждому родственнику. В свое время этот вопрос хорошо исследовал К. Аеви-Стросс (Lévi-Strauss, 1949).

Хотя общность, основанная на кровном родстве, является наиболее древней, но и по сей день она сохраняет свою значимость в некоторых областях жизни. Все мы знаем свою близкую родню и обращаемся именно к ней за помощью в разных бытовых ситуациях. Происхождение (т. е. кровное родство) играет первостепенную роль в определении членов клана, варны, касты, иногда сословия (например, принадлежности к дворянству или духовенству). Оппозиция сородич/инородец сохраняет свою значимость до сих пор.

В племени люди уже принадлежали к разным родам, их объединяла в основном единая культура, и дихотомия свой/чужой выглядела уже как соплеменник/иноплеменник. Основными определителями соплеменника были язык (диалект), бытовые обычаи, верования, участие в племенных обрядах и т. п. Иноплеменник, естественно, всего этого не знал или знал плохо и заметно отличался от соплеменников.

Но со временем племена начали объединяться в племенные союзы, началось формирование крупных этносов, разные диалекты основного языка выровнялись, то же выравнивание (стандартизация) произошло и с обычаями, и оппозиция соплеменник/иноплеменник обрела уже этнический смысл - представитель нашего этноса или иного. $\mathrm{K}$ началу аграрного периода понятие «соплеменники» уже определенно означало членов одного этноса. Главным отличительным признаком являлось то, что между соплеменниками была возможна коммуникация без переводчика (Флиер, 2012).

В аграрный этногосударственный период (привычные для нас рабовладение и феодализм) основу общественного сознания составляла религия (бывшая и основной политической идеологией эпохи) (Франкфорт и др., 1984). Истина воспринималась как абсолютная и универсальная. Соответственно в этот период дихотомия свой/чужой выглядела как единоверец/иноверец. Характерно, что даже человек, не владеющий местным языком, но принадлежащий к той же религии (деноминации), воспринимался как «свой» (Сурова, 2010: Электронный ресурс). Иноверец был чужим не только по религии, но еще и политически, ибо его вера не обязывала служить местному государю. 
Но в религиях, основанных на «священных текстах» (а это все основные религии, дожившие до наших дней), наблюдалось значительное расхождение между «книжной религиозностью», точно воспроизводившей основные вероучебные сентенции по книгам, и «народной религиозностью», более или менее вольно интерпретирующей их и часто смешивающей канонические догматы с предшествовавшим язычеством. Поэтому понятие «единоверец» весьма условно и не имеет четких критериев. А вот иноверец выделялся отчетливо, и единоверец нередко определялся именно в сравнении с иноверцем.

Принципы, лежащие в основании формирования социальных групп - родовой, племенной и этно-конфессиональный, - определяли и типы идентичности людей этого времени. Показательно, что сельские жители Руси называли себя не по роду деятельности - земледельцами, а по религиозной принадлежности - крестьянами (т. е. христианами).

В целом иррациональность, мистифицированность общественного сознания доиндустриальной эпохи отражалась и на отношении к чужому. Он воспринимался как инфернально «вредный», не понятный, опасный, не угодный нашему Богу, как не созданный по его образу и подобию, а являющийся порождением дьявола (Шапинская, 2011). И любые контакты с ним старались минимизировать.

\section{ПРЕАСТАВАЕНИЯ О СВОЕМ И ЧУЖОМ В ИНАУСТРИААЬНУЮ ЭПОХУ}

Ситуация заметно переменилась с наступлением индустриальной эпохи. В общественном сознании, по крайней мере, горожан религия постепенно становилось менее значимой, а возобладало буржуазное рациональное мировидение. Истина стала относительной, контекстуально зависимой. На базе этносов формировались нации, сочетавшие в себе этническое и политическое начала. Постепенно распространялась всеобщая грамотность, а с ней пришли и национальные культурные стандарты, вытеснившие многие религиозные стереотипы сознания (Флиер, 1998). Большую значимость получило государственное законодательное регулирование социального поведения людей.

Соответственно дихотомия свой/чужой обрела преимущественную форму соотечественник/иностранец. Иностранец, конечно, не так сильно отличался от своего, как иноверец или иноплеменник (по крайней мере, в границах одного культурного региона). Но его социальное поведение регулировали уже законы другой страны, что временами было очень заметно. А распространение национальных культурных стандартов значительно усиливало локальную специфичность поведенческого стиля и образа жизни соотечественников в отличие от иностранцев (Флиер, Полетаева, 2009).

Идентичность дюдей индустриальной эпохи определялась в первую очередь государственно-политическими условиями их существования, от которых отсчитывалось и все остальное. Ну и отношение к чужому соответствовало умонастроениям эпохи. Чужой, конечно, был иным, но по-своему интересным и, по крайней мере, рационально понятным. Он был просто «другим». И взаимодействие с ним было как минимум полезным, не всегда мирным (например, колониальное угнетение), но не опасным (Тлостанова, 2008).

Вместе с тем население любого государства индустриальной эпохи было этнически разнообразным, включало в себя множество субэтносов или этнических фрагментов соседних народов. Кроме того, население было многообразным по своему социальному составу, и нередко разные сословия говорили на разных диалектах, ориентировались на разные культурные эталоны. В этих условиях определение соотече- 
ственника было нелегким делом и нередко было также привязано к сравнению его с иностранцем, на фоне которого соотечественник выделялся более четко.

\section{ПРЕАСТАВАЕНИЯ О СВОЕМ И ЧУЖОМ В ПОСТИНАУСТРИАИЬНУЮ ЭПОХУ}

В постиндустриальную эпоху ситуация с этим вопросом опять переменилась. Производство сосредоточивалось уже не только на вещах и сооружениях, но в большой мере и на новых знаниях и информации. Основным производителем стала наука. Общественное сознание тоже изменилось. Оно отошло от крайностей предшествовавших эпох - сакрализации прошлого в доиндустриальную эпоху и романтизации будущего в индустриальную, а стало больше сосредоточиваться на настоящем и его критике (Флиер, 2015: Электронный ресурс). Характерной парадигмой постиндустриального сознания стал постмодернизм - концепция тотального сомнения во всем. Истина стала пониматься как что-то субъективное, как плод ангажированного сознания того или иного человека. Век книжной культуры сменился веком экранной культуры. Ажиотажное отношение переместилось с предстоящего светлого будущего на актуальную личную свободу, ставшую ключевым понятием общественного сознания. Аихотомия свой/чужой стала опираться в первую очередь на культурные различия между людьми. В русском языке нет соответствующих слов, так что эту оппозицию можно условно определить как «сокультурник/инокультурник».

Идентичность людей постиндустриального времени стала сложной, многоаспектной, а часто и просто ситуативной. В разных жизненных ситуациях человек стал определять себя по-разному. Отношение к чужому, наконец, стало безоценочным. Он не отвергается общественным сознанием постиндустриальной эпохи, но и не выделяется как что-то особенное. Чужой в новом понимании - это такой же человек, как и свой, и он столь же достоин личностной и культурной свободы, как и свой. Просто он носитель иной национально-культурной традиции и этим интересен. Фактически понятие «чужой» потеряло свой различительный смысл. Сопоставление свой/чужой уже стало не актуальным. Представители иного сословия или политические оппоненты часто воспринимаются как более чужие, нежели представители иного народа. В этом вопросе все относительно. Ведь люди все разные. В любом современном обществе есть люди, придерживающиеся прогрессистских взглядов на дихотомию свой/чужой, а есть и расисты, националисты, фундаменталисты, коммунисты, этатисты (фашисты) и пр. Поэтому сегодня идеологические различия между людьми играют бо́льшую роль, нежели оппозиция свой/чужой. В современном мире оппонент (в определенном смысле чужой) - это не инородец, иноплеменник, иноверец или иностранец. Это человек, придерживающийся иных взглядов на принципы социального мироустройства, т. е. иной политической культуры. И отторгается именно он, а не представитель иной расы, этноса, религии, страны.

\section{ЗАКАЮЧЕНИЕ}

Таким образом, мы видим, что отношение к чужому и возможности взаимодействия с ним от эпохи к эпохе менялось к лучшему. В доиндустриальную эпоху чужой отвергался в принципе как непригодный к какому-либо взаимодействию. В индустриальную эпоху взаимодействие с ним допускалось при определенных условиях (его культурной ассимиляции). А в постиндустриальную эпоху никаких препятствий к взаимодействию с чужим уже не усматривалось. Всякий акцент на отличии чужого от своего начал рассматриваться как архаический предрассудок. 
На протяжении человеческой истории в культуре всех народов эта дихотомия свой/чужой играла важную роль, в том числе определяя некоторые параметры идентичности своего. Именно благодаря сравнению с чужим наглядно были видны достоинства своего, оттачивались собственная идентичность человека и понимание себя самого. Аихотомия свой/чужой занимала заметное место в ряду всего комплекса многочисленных бинарных оппозиций в сознании людей любых эпох - доброе/злое, хорошее/плохое, сакральное/профанное, истинное/ложное и т. п., что составляло основу системы ценностных различений всей культуры.

В истории общественного сознания мы видим три типа чужих: чужой-инфернальный (имеющий адское происхождение), чужой-экзистенциальный (по жизни) и чужой-номинальный (по имени, по семиозису). Эти три типа, естественно, вызывали разное к себе отношение, исторически следовали один за другим, и с каждой эпохой отношение к чужому становилось все менее мистическим.

Можно говорить об исторической эволюции восприятия чужого в общественном сознании и как о пути постепенного отказа от крайностей деления социальной реальности на своих и чужих, а мира в целом на добрую (положительную) и злую (отрицательную) компоненты и глобальной культурной трактовки Универсума в рамках дуалистической парадигмы «правильное/неправильное». Этот вопрос в свое время основательно исследовал А. А. Пелипенко (Пелипенко, 2007). Такой вывод представляет собой важное теоретическое положение, показывающее, что общее построение культуры на основании бинарных оппозиций (что основательно исследовалось структуралистами и некоторыми иными учеными) (Аеви-Стросс, 1985; Пелипенко, 2012; Флиер, 2019: Электронный ресурс) имеет временный характер и в ходе истории постепенно преодолевается. Но эта тема лежит уже за пределами настоящего исследования.

\section{СПИСОК АИТЕРАТУРЫ}

Белл, А. (1999) Грядущее постиндустриальное общество. М. : Академия. 788 с.

Костина, А. В., Флиер, А. Я. (2009) Три типа культуры - три функциональные стратегии жизнедеятельности // Вестник Челябинской государственной академии культуры и искусств. № 2 (18). C. 23-36.

Иеви-Стросс, К. (1985) Структурная антропология. М. : Наука. 536 с.

Пелипенко, А. А. (2007) Ауалистическая революция и смыслогенез в истории. М. : МГУКИ. $434 \mathrm{c.}$

Пелипенко, А. А. (2012) Постижение культуры : в 2 ч. М. : РОССПЭН. Ч. 1. Культура и смысл. 607 с.

Сурова, Е. Э. (2010) Идентификационный принцип в культуре [Электронный ресурс] // Международный журнал исследований культуры. № 1. URL: http://www.culturalresearch.ru/ ru/archives/62-politics-of-ident (дата обращения: 28.11.2017).

Тлостанова, М. В. (2008) Аеколониальный проект: от политической деколонизации к доколонизации мышления и сознания // Аичность. Культура. Общество. Т. 10. №5-6 (44-45). C. $170-183$.

Флиер, А. Я. (1998) Массовая культура и ее социальные функции // Общественные науки и современность. № 6. С. 181-187.

Флиер, А. Я. (2006) Культура как репрессия. М. : Аиаграмма. 320 с.

Флиер А. Я. (2012) История культуры как смена доминантных типов идентичности // Иичность. Культура. Общество. Т. 14. № 1 (69-70). С. 108-122.

Флиер, А. Я. (2015) Аобро и зло в культурно-историческом понимании [Электронный ресурс] // Информационный гуманитарный портал «Знание. Понимание. Умение». №3. URL: http://www.zpu-journal.ru/e-zpu/2015/3/Flier_Good-Evil/ (дата обращения: 18.06.2019). 
Флиер, А. Я. (2019) Философские пролегомены к Нормативной теории культуры [Электронный ресурс]// Культура культуры. № 1. URL: http://cult-cult.ru/the-philosophical-prolegomenato-a-normative-theory-of-culture/ (дата обращения: 1.05.2019).

Флиер, А. Я., Полетаева, М. А. (2009) Происхождение и развитие культуры. М. : МГУКИ. 272 с.

Франкфорт, Г., Франкфорт, Г.А., Уилсон, Аж., Якобсен, Т. (1984) В преддверии философии. Ауховные искания древнего человека. М. : Наука. 236 с.

Фукуяма, Ф. (2004) Конец истории и последний человек. М. : АСТ. 488 с.

Шапинская, Е. Н. (2011) Образ Аругого в текстах культуры. М. : Красанд. 212 с.

Lévi-Strauss, C. (1949) Les Structures élémentaires de la parenté. Paris : PUF. 619 p.

Mason, P. (2015) PostCapitalism: A Guide to our Future. London : Allen Lane. 356 p.

Аата поступления: 02.09.2019 2.

\section{THE DEVELOPMENT OF VIEWS ON THE PHENOMENON OF "STRANGER" \\ IN THE HISTORY OF CULTURE \\ M. A. Poletaeva \\ MOSCOW STATE LINGUISTIC UNIVERSITY}

The article gives an overview of the evolution of ideas about one's own and a stranger in the history of mankind. This is the first attempt at a comprehensive scientific systematization of the typical views of society on this issue in history, which played a significant role in the formation of the national identity of people.

First of all, a number of variants of the division of history into periods are considered and the significance of its division into technological eras is substantiated: pre-industrial, industrial and postindustrial. The characteristics of each era necessary for this study are developed, and it is shown why in each era the attitude towards the dichotomy of own / stranger differed.

The pre-industrial era was characterised by the perception of someone else as being harmful, who should be dealt with as little as possible. A stranger is an enemy, a creature of the devil, and you should always be on guard with them.

In the industrial era, a stranger was perceived as a person different from a local, but not dangerous. It is possible to interact with them, especially with their sufficient assimilation in the local environment.

In the post-industrial era, a stranger is perceived only as a culturally different, but thereby interesting person. Interaction with them is just as possible as with one of their own.

Thus, in history there has been a certain evolution in the attitude of society towards the stranger from their predominant rejection to their predominant acceptance.

Keywords: own; stranger; pre-industrial era; industrial era; post-industrial era; history of culture

\section{REFERENCES} Russ.).

Bell, D. (1999) Griadusbchee postindustrial'noe obshchestvo. Moscow, Akademiia. 788 p. (In

Kostina, A. V. and Flier, A. Ia. (2009) Tri tipa kul'tury - tri funktsional'nye strategii zhiznedeiatel'nosti. Vestnik Cheliabinskoi gosudarstvennoi akademii kul'tury i iskusstv, no. 2 (18), pp. 23-36. (In Russ.).

Levi-Stross, K. (1985) Strukturnaia antropologiia. Moscow, Nauka. 536 p. (In Russ.).

Pelipenko, A. A. (2007) Dualisticheskaia revoliutsiia $i$ smyslogenez v istorii. Moscow, MGUKI. 434 p. (In Russ.).

Pelipenko, A. A. (2012) Postizhenie kul'tury : in 2 parts. Moscow, ROSSPEN. Part 1. Kul'tura i smysl. $607 \mathrm{p}$.

Surova, E. E. (2010) Identifikatsionnyi printsip v kul'ture. Mezhdunarodnyi zhurnal issledovanii kul'tury, no. 1 [online] Available at: http://www.culturalresearch.ru/ru/archives/62-politics-ofident (access date 28.11.2017). (In Russ.). 
Tlostanova, M. V. (2008) Dekolonial'nyi proekt: ot politicheskoi dekolonizatsii k dokolonizatsii myshleniia i soznaniia. Lichnost'. Kul'tura. Obshchestvo, vol. 10, no. 5-6 (44-45), pp. 170-183. (In Russ.).

Flier, A. Ia. (1998) Massovaia kul'tura i ee sotsial'nye funktsii. Obshchestvennye nauki $i$ sovremennost', no. 6, pp. 181-187. (In Russ.).

Flier, A. Ia. (2006) Kul'tura kak repressiia. Moscow, Diagramma. 320 p. (In Russ.).

Flier, A. Ia. (2012) Istoriia kul'tury kak smena dominantnykh tipov identichnosti. Licbnost'. Kul'tura. Obshchestvo, vol. 14, no. 1 (69-70), pp. 108-122.

Flier, A. Ia. (2015) Dobro i zlo v kul'turno-istoricheskom ponimanii. Informatsionnyi gumanitarnyi portal «Znanie. Ponimanie. Umenie», no. 3 [online] Available at: http://www.zpu-journal.ru/e-zpu/2015/3/Flier_Good-Evil/ (access date: 18.06.2019). (In Russ.).

Flier, A. Ia. (2019) Filosofskie prolegomeny k Normativnoi teorii kul'tury. Kul'tura kul'tury, no. 1 [online] Available at: http://cult-cult.ru/the-philosophical-prolegomena-to-a-normative-theory-of-culture/ (access date: 1.05.2019). (In Russ.).

Flier, A. Ia. and Poletaeva, M. A. (2009) Proiskbozbdenie i razvitie kul'tury. Moscow, MGUKI. 272 p. (In Russ.).

Frankfort, G., Frankfort, G.A., Uilson, Dzh. and Iakobsen, T. (1984) V preddverii filosofii. Dukbovnye iskaniia drevnego cheloveka. Moscow, Nauka. 236 p. (In Russ.).

Fukuiama, F. (2004) Konets istorii i poslednii chelovek. Moscow, AST. 488 p. (In Russ.).

Shapinskaia, E. N. (2011) Obraz Drugogo v tekstakb kul'tury. Moscow, Krasand. 212 p. (In Russ.). Lévi-Strauss, C. (1949) Les Structures élémentaires de la parenté. Paris, PUF. 619 p.

Mason, P. (2015) PostCapitalism: A Guide to our Future. London, Allen Lane. 356 p.

Submission date: 02.09.2019.

Полетаева Марина Андреевна - кандидат культурологии, доцент кафедры мировой культуры Московского государственного лингвистического университета. Адрес: 119034, Россия, г. Москва, ул. Остоженка, д. 38, стр. 1. Тел.: +7 (499) 246-20-62. Эл. адрес: m.poletaeva@mail.ru

Poletaeva Marina Andreyevna, Candidate of Culturology, Associate Professor, Department of World Culture, Moscow State Linguistic University. Postal address: 38, Bldg. 1, Ostozhenka St., Moscow, Russian Federation, 119034. Tel.: 8 (499) 246-20-62. E-mail: m.poletaeva@mail.ru

DOI: $10.17805 / z p u .2019 .4 .14$

\title{
Социокультурный феномен эффективной коммуникации на примере детских эмигрантских журналов в Маньчжурии
}

\author{
Ю. А. ГОЛОВИН, О. Е. КОХАНАЯ \\ МОСКОВСКИЙ ГУМАНИТАРНЫЙ УНИВЕРСИТЕТ
}

Авторы рассматривают специфику создания и функционирования детских эмигрантских периодических изданий в китайской Маньчжурии, в частности одного из самых популярных эмигрантских изданий Дальнего Востока журнала «Ласточка». Он выходил в г. Харбине с 1926 по 1945 г. Журнал расценивается как самобытный социокультурный институт, который стал охранителем русских культурных традиций, созидателем их в новой 